\title{
Sensibilidad dentaria
}

\author{
Tortolini P*
}

\section{RESUMEN}

La sensibilidad dentaria l es un problema común que se presenta entre el 9 y el $30 \%$ de la población adulta. La teoría hidrodinámica es aceptada como uno de los mecanismos de inducción de la respuesta pulpar dolorosa, debido a que los estímulos provocan el movimiento del fluido y para ello es necesario que la dentina este expuesta y que los túbulos dentinarios estén abiertos y permeables a la pulpa.

Es fundamental realizar el diagnostico diferencial con otras causas de dolor dental e identificar los factores etiológicos y predisponentes.

Palabras claves: hipersensibilidad dentinaria - Etiología- Blanqueamiento Dentario.

\section{SUMMARY}

Dental sensitivity is a common problem and it affect 9 and $30 \%$ the adult poblation. The hidrodynamyc theory is cited as the menchanism of induction of a painful pulpal response and implies that stimuli tranmission across dentine increase the rate of fluid flow through dentinal tubules and for this to accur the dentinal tubules must be opened andpermeable to the pulp.

An appropiate tretametn needs a diferential diagnosis eith other causes of dental pain and the identification of predisponing etiologic factors.

Key words: Dentinal Hipersensitivity - Etiology - Tooth Beaching

Aceptado para publicación: Marzo 2003.

* Docente de Periodoncia de la Facultad de Odontología. Universidad Nacional de Córdoba. Argentina.

Tortolini P. Sensibilidad dentaria. Av. Odontoestomatol 2003; 19-5: 233-237.

\section{IINTRODUCCIÓN}

Sensibilidad dentaria es la respuesta dolorosa de la dentina ante ciertos estímulos normales, térmicos químicos o táctiles.

Aparece en restauraciones defectuosas, caries, cúspides rotas, tratamientos conservadores, bruxómanos, etc.

Las 2 causas más frecuentes de su aparición son: la pérdida de esmalte (atrición, bruxismo, abrasión, erosión) y la recesión gingival (enf. periodontal, cepi- llado, traumatismos y cirugía periodontal).

La exploración microscópica de las superficies clínicamente hipersensibles ha demostrado que son áreas de dentina expuesta por retracción gingival, abrasión, erosión terapéutica periodontal, restauraciones defectuosas o caries.

Los tratamientos dentales pueden iniciar o favorecer la aparición de los síntomas.

Las técnicas periodontales pueden crear o aumentar la exposición de las superficies radiculares. 
Las caries o preparaciones de coronas por el profesional también inducen sensibilidad, lo mismo pueden producir las coronas temporales o permanentes sobre los dientes tallados y las técnicas de blanqueamientos dentales.

Estudios realizados demuestran que entre el 9 y el $30 \%$ de la población adulta padece de hipersensibilidad. La incidencia de hipersensibilidad aumenta con la edad hasta los 40 años siendo más frecuente en personas de ambos sexos entre 20-30 años de edad.

A partir de los 40 años hay una disminución de hiperestesia dentinal, probablemente debida a cambio escleróticos en los túbulos dentinarios cuyo diámetro disminuye gradualmente con la edad resultando en una reducción en el movimiento del fluido dentinario.

La hipersensibilidad más común es al frío siendo más frecuente encontrarla en los caninos (25\%) luego en los premolares (24\%), observándose más en las caras vestibulares (93\%) y generalmente asociadas a recesiones gingivales $(68 \%)$.

Se estima que las piezas dentarias que transmiten mayor sensibilidad dolorosa son los incisivos seguidos por los premolares y molares.

La variación entre una pieza dentaria y otra está relacionada con el espesor de la dentina y el esmalte.

La sensibilidad también puede darse en superficies oclusales que hayan perdido en forma parcial o total el esmalte debido al bruxismo o mal posiciones dentales.

La mayoría de los tratamientos que se realizan en la cavidad bucal dañan los tejidos duros y blandos recibiendo agresiones de diferente magnitud que comportan respuestas variables, reversibles o no.

La patología pulpar por iotrogenia periodontal deriva de la posible exposición de la dentina radicular.

La hipersensibilidad dentinaria se presenta con frecuencia debido por un lado, a la exposición radicular tras el alisado y por otro a los cambios inflamatorios o hemorragicos en las pulpas dentales.

El cemento intacto es la mejor barrera para impedir el paso hacia el interior de la dentina. Si se elimina el cemento en el alisado, se pierde ésta protección.

A veces el raspaje profundo puede dejar al descubierto los conductos laterales accesorios creando comunicación directa del exterior al tejido pulpar.

La hiperestesia dentinal varía en intensidad. Puede ser desde moderada hasta extremadamente dolorosa. En algunas personas la hiperestesia es tolerable mientras que en otras es un problema que afecta su calidad de vida, sus hábitos de higiene oral e incluso el tipo de alimentos que toman. De acuerdo a la tolerancia de cada individuo se puede clasificar en 3 categorías:

Sin sensibilidad

Con sensibilidad moderada

Con sensibilidad extrema

Los estímulos que producen hipersensibilidad pueden ser de 3 tipos:

\section{MECÁNICOS}

Mecánico directo durante la instrumentación dental

- Trauma mecánico, puede ser el resultado del cepillado incorrecto que causa retracción gingival y abrasión de la superficie radicular

- Pacientes que desgastan sus dientes en exceso, presenten con frecuencia sensibilidad dental. La pérdida del esmalte en los bruxomanos causa dolor.

\section{QUÍMICOS}

Otra causa de exposición dentinaria con dolor sería la ingesta de ácidos que pueden lesionar químicamente la dentina. Los alimentos dulces, amargos o ácidos pueden causar dolor; dentro de estos esta el blanqueamiento.

\section{TÉRMICOS}

Causados por la ingesta de alimentos líquidos fríos o calientes o cuando aire frío contacta con zonas de dentina expuesta. 


\section{EROSIÓN}

También llamada perimilolisis o perimolisis.

Es el gravado químico y disolución, también podemos decir que es la progresiva pérdida de esmalte y dentina poco dolorosa producida por una agresión química de ácidos y/o quelantes sin la intervención de bacterias (Eccles, 1978; Robb 1991); no debiendo olvidarnos de la calidad (composición), como la cantidad (flujo) de la saliva; eso puede ocurrir en sitios del diente libre de placa bacteriana.

Esta lesión afecta más frecuentemente a los jóvenes, y es más común en las mujeres.

\section{Hay distintos tipos de Erosión:}

\section{a) Erosión dada por factores ambientales:}

Se da en profesiones o trabajos en los que tienen una diaria exposición a ácidos.

EJ: trabajadores de fábricas de municiones de dinamita, imprentas, laboratorios (pipetean ácidos), catadores de vino, en los que trabajan con aerosoles ácidos (fabricas de baterías), en nadadores profesionales (piscinas cloradas con gas), los electroplateros, conservadores de frutas.

\section{b) Erosión por dieta:}

El agente etiológico es la ingesta de alimentos y bebidas ácidas, como el consumo de cítricos y bebidas de bajo PH. Los ácidos más activos en la formación de erosiones son el ácido fosfórico, tartárico láctico, siendo el ácido carbónico el menos erosivo (Järvinen -1991).

Estos afectan dependiendo de la frecuencia y duración de la ingesta.

Se ven desgastes en las superficies palatinas y bucales de los dientes anteriores y posteriores de la arcada superior sin mayor repercusión en las superficies linguales de los dientes de la arcada inferior.

\section{c) Erosión por medicamentos:}

Se da cuando se usan por largo tiempo o en dosis elevadas:

- Tonicos de hierro (debido a su bajo Ph.)

- La vitamina C (ácido clorhídrico)

- La aspirina (ácido acetil salisílico) en pacientes con artritis reumatoidea juvenil

- Enjuagatorio antisarros (que contienen EDTA por acción quelante)

- Estimuladores de producción de saliva (ácido cítrico y maleico)

\section{d) Erosión debido al ácido gástrico:}

En pacientes que padecen alteraciones del tracto digestivo o presentan vómitos recurrentes o regurgitaciones (gastriris con pirosis - bulimia -anorexia).

\section{ATRICIÓN}

Proceso mecánico que involucra contacto diente con diente. La atrición fisiológica es la pérdida regular y gradual del diente como consecuencia de la masticación fisiológica pudiendo afectar todas las superficies del diente; en cambio la atrición patológica sería causada por una función anormal o por la inadecuada posición de los dientes que estaría limitada a un diente o un grupo de dientes y se puede presentar en alteraciones de la oclusión, en el prognatismo mandibular y en el bruxismo; en ciertos hábitos dietéticos que contengan alimentos abrasivos en alteraciones de la mineralización de los dientes como la amelogenesis y la dentinogenesis imperfecta, en la hiposialia y xerostramía.

Ericsson ha demostrado que en las áreas de atrición, la dureza es mayor debido a que su contenido mineral era el $8 \%$ mas alto.

Se produce en adultos y personas mayores, generalmente en hombres.

\section{ABRASIÓN}

- Proceso mecánico que involucra objetos o sustancias extrañas. Es la pérdida o desgaste patológico 
del tejido duro del diente debido a la fricción de un cuerpo extraño, independiente de la oclusión; o también podemos decir que es el desgaste de una estructura como es el diente como consecuencia de un proceso mecánico anormal.

Según su etiología puede ser:

\section{Abrasión por cepillado}

Suele comenzar en la unión amelocementaria y asienta en la raíz; produciéndose previamente áreas de recesión gingival.

Se dan generalmente en las zonas cervicales de las superficies vestibulares de incisivos, caninos y premolares, sobre todo en el maxilar superior, produciendo en algunos casos gran sensibilidad.

Hay estudios que indican que esto es debido a los movimientos incorrectos de la técnica de higiene, a la abrasividad de las pastas dentales y en menos grado al tipo de cerdas del cepillo dental.

Abrasión por retenedores de prótesis

Se ha demostrado que el efecto de las prótesis no es el causante de la abrasión; sino la retención de los alimentos a ese nivel y a la formación de ácidos.

\section{Abrasión por hábitos adquiridos}

Dentro de estos tenemos los fumadores de pipa, costureras, zapateros, peluqueras, sopladores de vidrio, músicos de instrumentos de viento.

Estos se pueden dar a cualquier edad y con mayor frecuencia en hombres.

\section{Blanqueamiento dentario}

Cuando se hace blanqueamiento los pacientes deben saber sobre la posibilidad de dolor, pero también deben saber que es reversible con molestias a los cambios térmicos y que la sensibilidad cuando existe, desaparece a las 24 hs. posteriores al uso del blanqueador al remineralizar los dientes con compuestos fluorados (Schmidseder y cols, 1998).

El blanqueamiento dental no siempre es el causante de la sensibilidad según Velez Vargas, pero de hecho, se la aumenta en pacientes con sensibilidad manifiesta.
Estas técnicas de aclareamiento dental están asociadas a la sensibilidad durante el tratamiento debido a las siguientes causas: desecación - deshidratación presión de aire, cambios en la osmolaridad, cambios de temperatura y $\mathrm{PH}$.

La explicación a este fenómeno es el paso de los agentes (de bajo peso molecular) a través del esmalte, dentina y cemento ingresando fácilmente a la cámara pulpar; no influyendo el $\mathrm{Ph}$ que posea la solución, lo que fue demostrado por Cooper en 1992.

En lo referente a la irritación pulpar, estudios indican que histológicamente la pulpa no se ve afectada significativamente, incluso si el peróxido de hidrógeno llega a ella no existe un daño irreversible (Perdigao 2001).

\section{DISCUSIÓN}

Numerosos estudios ponen en evidencia que hay diferentes formas de procesos destructivos crónicos que afectan a los dientes de la carie dental, además de la carie dental produciendo una pérdida irreversible de la estructura dentaria encontrándose entre ellos, la abrasión, atrición, resorción, erosión y demasticación.

Estas lesiones pueden ser fisiológicas y/o patológicas. Todos estos procesos destructivos has existido desde tiempos prehistóricos de acuerdo a los hábitos de cada época Ej: cuando el hombre utilizaba sus dientes para triturar alimentos abrasivos; en la actualidad con el cambio de estilo de vida, se ven nuevos hábitos como el cambio de dieta, aumentando el consumo de bebidas carbonatadas y buscando una figura estética aceptada (bulimia y anorexia).

Cuando la dentina y el cemento quedan expuestos como consecuencia de la recesión gingival, los estímulos externos táctiles, térmicos o químicos pueden desencadenar una sensación dolorosa conocida como hipersensibilidad dentinaria.

\section{CONCLUSIÓN}

Con la información obtenida nosotros como odontólogos debemos conocer y estar alerta a estos cambios para actuar de manera oportuna para que estos 
daños no sean irreversibles; así estaremos en condiciones de brindar solución terapéutica y preventiva.

\section{BIBLIOGRAFÍA}

1. Cooper PJ. Charnock J. The prevalence of bulimia nervosa. Br. J. Psychiatry 1987; 151: 684-6.

2. Everett B Hancock Prevención Ann Periodontal 1996; 1: 223-49.

3. Fischer C, Fischer RG, Wennberg A. Prevalence and distribution of cervical dentine hypersensitivity in a population in Rio de Janeiro, Brazil. J Dent 1992; 20: 272-6.

4. Hipersensibilidad dental - Clínicas Odontológica de Norteamérica Nueva Edición Interamericana S.A. Mexico Vol 3; 1990.

5. Imfeld T. Dental erosión. Definition Classification and links. Eur. J Oral Sci 1996; 104: 151-5.

6. Prof. Dra Yanett Mas López. Alerta ante una amenaza creciente: Erosión dental. Estética y Operatoria Dental. Lima - Perú 2002; 159-62.

7. Prof. Dr. Jaime Sarmiento Cornejo-Bioseguridad en el blanqueamiento dentario. Estética y Operatoria Dental. Lima - Perú 2002; 133-7.

8. Kohen Sergio, De Franceschi C, Rodriguez G. Estética del color dentario: "Blanqueamiento Integral" 2002; 29: 75-7.
9. Malva, A: Recesiones y abrasiones por cepillado. Prof. Dental 1983; 23: 13-7.

10. Nathanson D, 1997 "Vital tooth bleaching: sensivility and pulpar considerations. J Amen Dent Assoc, 1997; 128 (april): 41-4.

11. Nathanson D, "Vital bleaching and pulp considerations" Jada 1997; 28 (Sup): 415-55.2.

12. Pashley Dh. Merchanism of dentin sensivity Dent Clin North Am 1990; 34: 449-73.

13. Rafael Rioboo Higiene y prevención en odontología Ediciones Avances 1994; 23: 592-8.

14. Rugg-Gunn A J. Nutrition and dental health Oxford Medical Publications 1993.

15. Sherman A y Jacobsen Pl. "Managin dentin hypersensitive" J. Amer Dent Assoc. 1992; 123 (4): 57-61.

16. Sobral MA. Luz M de C. Goma - Texeira A Garone Netto N. Influencia da dieta liquida ácida no desenvolvimiento de erosao dental. Pesqui Odontol Bras 2000; V 14, n4, p 406-10.

\section{CORRESPONDENCIA}

Dra. Patricia Tortolini

Ituzaingo 1035 - Córdoba- (5000) Argentina.

e-mail: bodereau@sinectis.com.ar 
